\title{
SIII-2a
}

\section{ENERGY RECOVERY FROM SEWAGE SLUDGE AND \\ FERMENTABLE FRACTIONS OF SOLID WASTE FROM THE CITY OF SOKODE BY CO-DIGESTION}

\author{
Nitale M'Balikine KROU ${ }^{(1)}$; Gnon BABA ${ }^{(1,2)}$; Kwamivi N. SEGBEAYA ${ }^{(1,2),}$ Ogouvidé \\ Akpaki ${ }^{(1)}$ \\ E-mail : krounitale@gmail.com ; gnonbaba@gmail.com ; kwamininnyo@gmail.com;
}

\begin{abstract}
One of the consequences of the improvement of the living conditions of the populations is the strong demand in thermal energy for the households whereas in the developing countries, the cost of living is a brake with all the social layers to reach supply of butane gas for their energy needs. This study takes place in the context of energy, environmental and sanitation challenges in the city of Sokodé. Indeed, we are witnessing more and more growing needs for butane gas, firewood or charcoal for cooking or lighting in the city of Sokodé as everywhere in other cities of the same size. Thus by the production of energy in situ, the condition of the populations will be able to improve significantly thanks to the recovery of sludge and fermentable fractions of solid waste into biogas. The objective of this work is to produce and recover methane from fermentable waste produced in the city of Sokodé. The methane or biogas recovered will be used as fuel to fuel kitchens in households. The resulting digestate will serve as an organic amendment to agricultural soils in the commune of Sokodé. Laboratory scale tests have been carried out to validate the value of co-digestion of sewage sludge with fermentable solid waste. The results obtained have shown that the methanogenic potential of sewage sludge is low compared to that of fermentable solid waste. The codigestion of the two products allows a greater production of methane representing an energy gain compared to the methanisation of the sewage sludge alone. This study shows that waste (sludge from public septic tanks, waste from markets, hotels and fermentable households) can be considered an appreciable energy resource. Their Co-treatment would, while reducing the nuisance associated with this waste, produce valuable energy.
\end{abstract}

Keywords : Renewable energy; Anaerobic Co-digestion; Organic solid waste; drain sludge.

\section{Introduction}

One of the consequences of the improvement of the living conditions of the populations is the high demand for thermal energy for the households whereas in the developing countries, the cost of living is an obstacle to all the social layers to reach supply of butane gas for their energy needs. Generally in these countries, the most used source of energy in the households is that of charcoal. Excessive use of wood and charcoal leads to deforestation which in turn has a negative effect on the environment. According to the 2010 World Bank report on the energy balance in Togo, biomass remains the main source of energy consumed. It represents on average 70 to $80 \%$ of total final consumption and is used to supply the domestic and craft sectors. According to the same report, nationally (Togo), $61 \%$ of households use only wood,

\footnotetext{
${ }^{1}$ Laboratory of Sanitation Water Sciences and Enviroment (LASEE), Faculty of Science and Technology, Department of Chemistry, University of Kara (Togo), BP.404 Kara-Togo, mail: oakpaki@gmail.com

${ }^{2}$ Laboratory of Mangement, Treatment and valuation of Waste (GTVD), Faculty of Science, 
$24 \%$ charcoal and firewood and $15 \%$ only charcoal, $75 \%$ of rural households use firewood with a consumption of $347 \mathrm{~kg} /$ year / person, while $72 \%$ of urban households use charcoal for around $59 \mathrm{~kg} /$ year / person [1]. With this vertiginous consumption of wood which is likely to increase in the coming years and that, at the current state of our knowledge, no concrete measure is taken to balance the consumption of wood energy with the production capacity of forests, it can be estimated that Togo is tending towards a chronic inability to meet its wood energy needs and to the disappearance of the forests which constitute the sources of supply. This increased consumption of wood and the strong degradation of forests in Togo is due to the cost of fossil fuels and the difficulty of serving landlocked regions.

At a time when renewable energies are more and more mentioned to supplement or gradually replace fossil fuels, anaerobic digestion is an opportunity to diversify energy resources and to manage the environment sustainably. Anaerobic digestion has significant potential through its double capacity for recovering energy from organic waste and reducing greenhouse gas emissions. It could be seen as an economic, decentralized and ecological solution to these problems through energy autonomy and sustainable agricultural development in rural areas.

This study takes place in the context of energy, environmental and sanitation challenges in the city of Sokodé. Indeed, we are witnessing more and more growing needs for butane gas, firewood or charcoal for cooking or lighting in the city of Sokodé as everywhere in the other cities of the same size. Thus by the production of energy in situ, the condition of the populations will be able to improve significantly thanks to the recovery of sludge and fermentable fractions of solid waste into biogas. The wood and charcoal which constitute the traditional biomass in households in Sokodé generate smoke which is a threat to public health. Co-fermentation of sewage sludge with fermentable waste of domestic or industrial origin can be a good alternative for domestic cooking.

Small-scale biogas fermentation systems offer the possibility of using the waste substrates mentioned above and therefore saving public health, instead of using wood (smoke is also dangerous).

The general objective of this work is to produce and recover methane from fermentable waste produced in the city of Sokodé. The methane or biogas recovered will be used as fuel to fuel kitchens in households. The resulting digestate will serve as an organic amendment to agricultural soils with good fertilizing value in the commune of Sokodé. In fact, all of the nitrogen contained in the methanised material is conserved during anaerobic digestion. However, there is a change from the original organic form to an ammoniacal $\mathrm{NH}_{4}^{+}$form which is more assimilable by plants [2]. The present study aims in particular to evaluate the interest of Co-digestion of sewage sludge with fermentable waste through their maximum production of biogas and methane.

As far as we know, no study has been reported on the Co-digestion of sewage sludge with fermentable municipal waste in Togo. This study could provide a baseline database in Togo using inexpensive and available raw materials that complement each other.

Tests on a laboratory scale have been carried out in order to validate the value of the Codigestion of the sludge with the fermentable solid waste.

The results obtained will enable the process to be validated and implemented on a large scale at the sewage sludge treatment station in the city of Sokodé.

\section{Materials and methods}




\subsection{Description of the study environment}

Organic waste used in this research came from Sokodé, capital of the Central Region and the Prefecture of Tchaoudjo, located between $8^{\circ} 57$ 'and $9^{\circ} 03^{\prime}$ of Latitude North and $1^{\circ} 05$ 'and $1^{\circ} 11^{\prime}$ of Longitude East, $346 \mathrm{~km}$ north of Lomé. It has long been the regional capital of the northern zone and especially the second center of settlement of the country. With a population estimated at 111258 inhabitants, Sokodé enjoys a tropical climate of transition between Guinean (wet) and Sudano-Sahelian (dry).

\subsection{Raw materials}

\subsubsection{Origin of substrates and scenarios}

The sludge used comes from public toilets. Preliminary modeling studies of biogas production by sludges from dry latrines (DL), public septic tanks (PST) and domestic septic tanks (DST) from the city of Sokodé have shown that DST and DL sludge have a low production of biogas compared to that of PST sludge. Thus, only fresh sludge (from public toilets) is suitable for the production of biogas, with a dryness of at least 3\% [3]. Fermentable fractions are obtained after sorting solid waste from hotels, markets and households. The samples used for the experiments were taken in accordance with good sampling and conservation practices.

The test includes four scenarios :

- Scenario $1:$ feeding the digester with the drain sludge alone,

- Scenario 2 : feeding the digester with the fermentable fractions of household waste only,

- Scenario 3 : feeding the digester with the fermentable fractions of market and hotel waste alone,

- Scenario 4 : feeding the sludge drain digester mixed with the fermentable fractions of solid waste (households, hotels and markets).

Tests carried out under a mesophilic regime $\left(37^{\circ} \mathrm{C}\right.$.) consisted in monitoring the performance of biogas production by these residues.

\subsubsection{Ratios}

The solid / liquid ratio (S / L) equal to $1 / 5$ has been used [4] because it makes it possible to avoid inhibitions and makes it possible to reach the maximum production of biogas for most substrates [5] and [6]. Thus, to prevent inhibitions, the amount of substrate used is not too large compared to the amount of distilled water. This optimal S / L ratio of $1 / 5$ fixed will also allow bacteria to ensure the fermentation of organic matter, limiting the concentration of nitrogen and / or volatile fatty acids [7].

After mixing the substrates and distilled water, the vials were closed tightly. The vials were then incubated at $37^{\circ} \mathrm{C}$ to perform digestion under mesophilic conditions. The experiments were stopped after 42 days of production when the daily production of biogas was very low.

\subsubsection{Grinding}

Reducing the particle size of the substrate increases its homogeneity. This reduction in size is necessary because the specific surface that can be attacked by bacteria and enzymes increases with the reduction of particles [8]. In addition, large particles originally can be introduced into small laboratory bottles by grinding. Studies on the effect of grinding food scraps have also been carried out. The results showed that a reduction in particle size to $2 \mathrm{~mm}$ allows an increase in methane production of at least $20 \%$ [9]. Grinding would release easily degradable particles, which are not always available to bacteria without reducing the particle size [10] 
and [11]. In this study, the grinding was done using a laboratory mortar to reduce the particle size. The following pictures show the samples of fresh sludge and fermentable fractions of solid waste

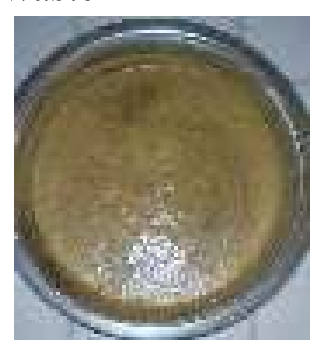

Figure 1: Sample of fresh sewage sludge

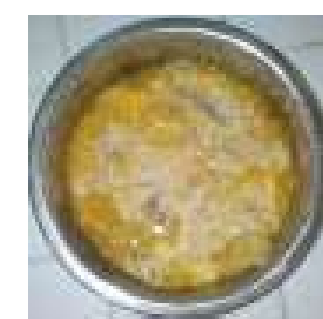

Figure 2: Sample of FFAW

\subsection{Biogas production test: experimental protocol}

The protocol is based on preliminary studies in laboratory pilot. This protocol implemented makes it possible to obtain the total biogas production of the effluent representative of its level of anaerobic biodegradability. The experimental device is made up of digesters $(1500 \mathrm{~mL}$ bottles), rubber pipes, graduated cylinders for collecting biogas, a solution of sodium chloride contained in a beaker and supports. In this assembly, the pilot digesters were connected through gas supply pipes, to inverted test tubes (allowing the visual measurement of the volume of biogas produced daily) immersed in a beaker containing a trap solution, consisting of saturated water in $\mathrm{NaCl}$ and in acid (hydrochloric acid $5 \%, \mathrm{NaCl} 20 \%$ and $\mathrm{pH}=2$ ) in order to minimize the dissolution of $\mathrm{CO} 2$ from the biogas [12] and [13]. This aqueous solution traps, by the displacement of the liquid, to properly quantify the daily production of biogas (Figure 3).

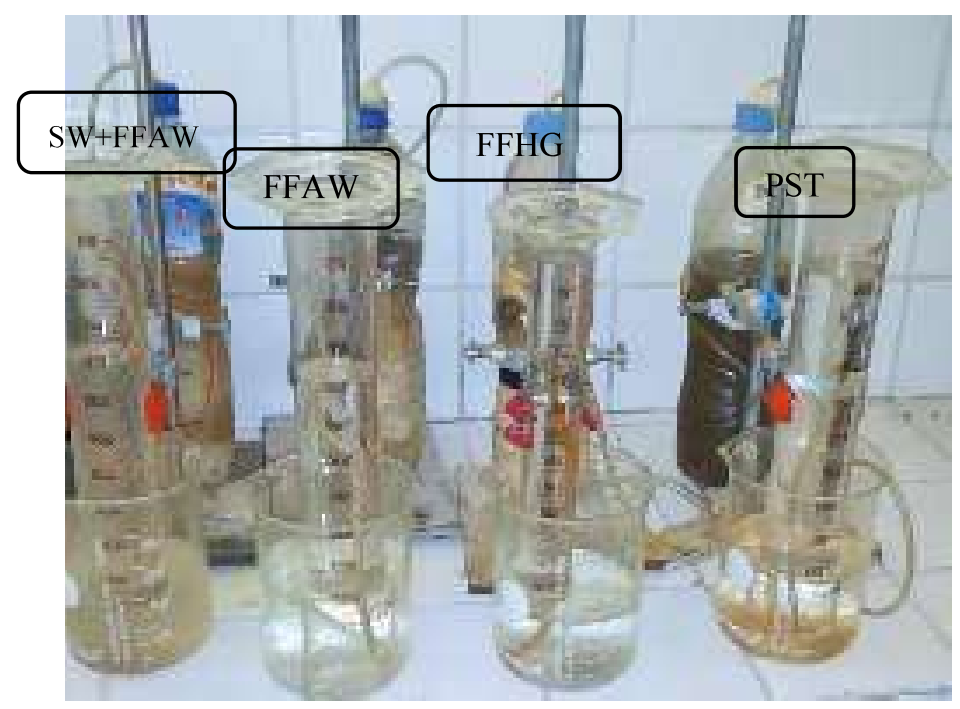

Figure 3: Biogas production system

\section{Results and discussion}

In order to validate the value of the co-digestion of sewage sludge with the fermentable fractions of municipal solid waste, a comparative study of the production of biogas from these different fermentable substrates was carried out.

\subsection{Co-digestion scenario performances}

3.1.1. Biogas production by different fermentable substrates 
The production measured represents the maximum amount of biogas that can be produced by a given fermentable substrate. This measurement is specific to each fermentable substrate and representative of its level of biodegradability. Figure 4 shows the cumulative biogas production for an anaerobic digestion of 42 days. Depending on the type of substrate, biogas production varies depending on whether it is rich in easily biodegradable organic matter.

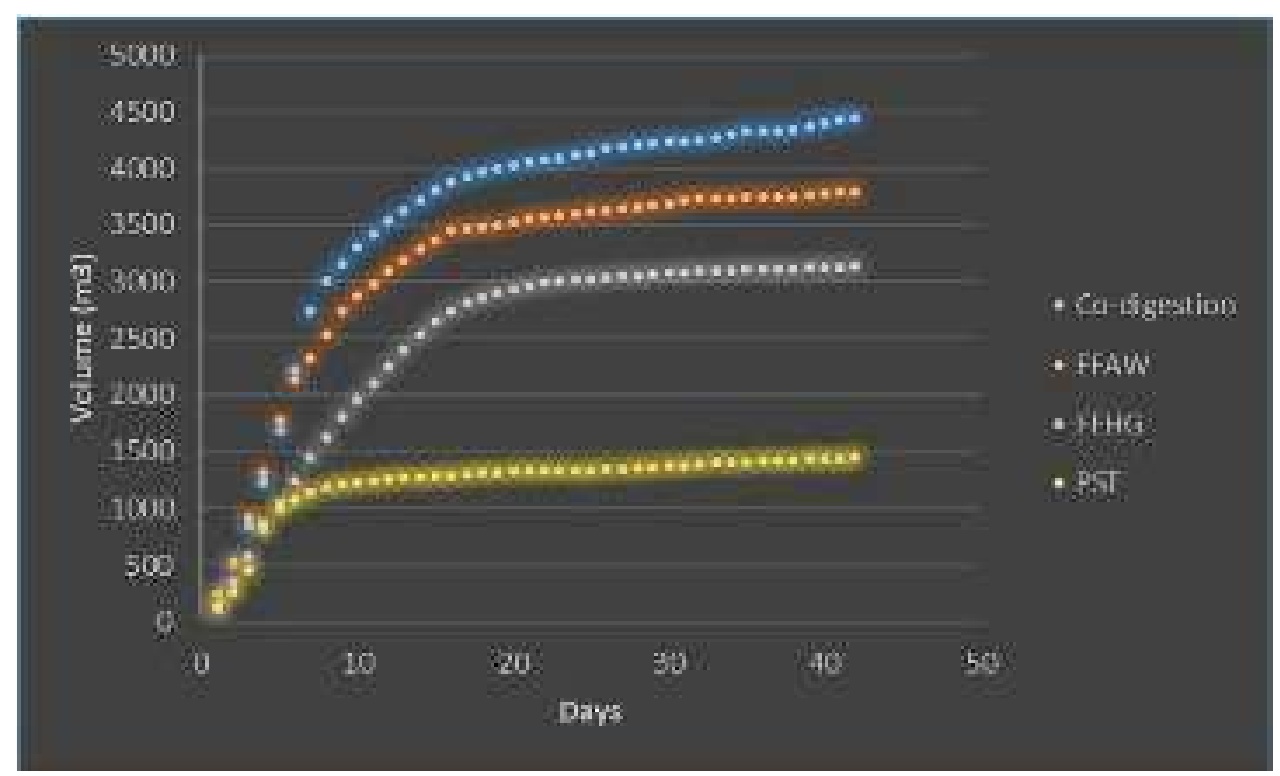

Figure 4 : Cumulative biogas production

* FFHW : Fermentable Fractions of Household Waste (Corn paste, prepared rice, prepared pasta and mango).

* FFAW : Fermentable Fractions of Assimilated Waste (Mango, banana, bread, and avocado).

* PSP : Public Skeptic Tank

This figure shows that, from the same quantity of substrate, the biogas production potential of FFAW is high compared to that of FFHW, which is also higher than that of sewage sludge from public septic tanks. This result is explained by the fact that the biologically degradable part is higher at the fermentable fractions of solid waste than at the level of the sludge; these sludges having already undergone decomposition in the pits thus reducing their digestible matter content. The high biogas production of FFHW (leftover corn dough, prepared rice, prepared pasta) compared to that of sewage sludge is attributed to the presence of residual food starch in these effluents [12]. Waste materials have a low level of biodegradability compared to other substrates. It may be a problem of accessibility of the organic matter or of the composition of the organic matter or else of the limitation of the fermentation by ammonia in more or less significant concentration in these sludges [12]. The best performance of FFAW effluents is attributed to their high organic matter content in the waste because the amount of gas produced by a substrate is positively correlated with the amount of organic matter present [14]. Indeed, most of the fruits used in this scenario are rich either in lipids (example of avocado), or in starch (bread for example), or in carbohydrates (banana). Studies have also shown that the main constituents of mango are water, carbohydrates, proteins, fats (carotene), minerals, pigments, tannins and vitamins [15]. However, lipid products have a high potential for biogas production as well as the methane content [12]. In addition, it has 
been shown that fruit residues often have high methanogenic potential and are easily assimilated by bacteria. This assimilation is due to the high contents of pectins at the level of their cell walls and of easily biodegradable organic acids, giving them a relatively rapid kinetics of anaerobic degradation [16]. The organic matter provided by FFAW is much more easily degradable than that from FFHW, which results in their much higher gasification potential.

The results presented indicate that, the association of these fermentable fractions of various origins will allow to improve the individual performances, which allowed us to formulate another hypothesis on the investigation compared to the anaerobic Co-digestion of these sludges with the fermentable fractions of municipal solid waste.

\subsubsection{Interest of Co-digestion}

The results of co-digestion (Figure 4) show that the production yield of biogas has improved significantly compared to the digestion of these substrates alone. The biogas production potential is increased by almost $35 \%$ compared to the phase without the addition of cosubstrates (on average 3,580L/gMO compared to $1.233 \mathrm{~L} / \mathrm{gMO}$ ) for the sludge. The contribution of co-substrates of lipidic nature allowed an increase in the quantity of biogas produced daily as well as the content of methane [12]. Also, the addition of fermentable fractions of municipal solid waste leads to an increase in the rate of organic matter compared to the phase of sewage sludge alone., As a result, there is a greater production of biogas. The present study shows that a ratio equal to 0.3 gives better biogas production. This result is comparable to that obtained by.Nsavyimana where a sludge VSM/waste VOM ratio $=0.3$ was considered optimal for good digestion of waste of a different nature [17].

The biogas produced from the co-digestion of sewage sludge with fermentable market waste contains on average $65.6 \% \mathrm{CH} 4$ against $34.4 \% \mathrm{CO} 2$ ) [18]. On this basis, we estimated volumes of methane and carbon dioxide in the biogas produced. Indeed, from $1 \mathrm{~L}$ of substrate in 42 days of Co-digestion, an average production of $3.580 \mathrm{~L} / \mathrm{g}$ MO was estimated, that is to say a volume of $2.348 \mathrm{~L}$ of $\mathrm{CH} 4$ and $1.232 \mathrm{~L}$ of $\mathrm{CO} 2$.

\section{Conclusion}

The general objective of this study was to produce and recover methane from fermentable waste produced in the city of Sokodé. It is particularly a question of evaluating the interest of Co-digestion of drain sludge with fermentable waste through their maximum production of biogas and methane. The results of the pilot tests on a laboratory scale demonstrate the significant variability that may exist between fermentable residues of different origins. From the same quantity of substrate, the biogas production potential of the fermentable fractions of assimilated waste (from markets, hotels) is high compared to that of the fermentable fractions of household waste, which is also higher than that of emptying from public septic tanks.

Sewage sludge alone has a low production of biogas compared to the fermentable fractions of municipal solid waste. The addition to fermentable sludge under controlled conditions of the fermentable fractions of municipal solid waste with a higher dry matter content has made it possible to increase the production performance of biogas compared to sewage sludge alone. The biogas production potential is increased by almost $35 \%$ compared to the phase without the addition of co-substrates (on average $3.580 \mathrm{~L} / \mathrm{g}$ MO compared to $1.233 \mathrm{~L} / \mathrm{g} \mathrm{MO}$ ) for the sludge. From 1L of substrate in 42 days of Co-digestion, an average production of $3.580 \mathrm{~L} / \mathrm{g}$ MO was estimated, ie a volume of $2.348 \mathrm{~L}$ of $\mathrm{CH} 4$ and $1.232 \mathrm{~L}$ of $\mathrm{CO} 2$. The results thus 
obtained clearly show the interest of the co-digestion of this waste and constitute basic data for the large-scale implementation of this co-digestion on the sewage sludge treatment station of the city of Sokodé. The gas produced will reduce the gas stock problem and supply households with butane gas. The use of this green technology (anaerobic digestion), will avoid the emission of harmful greenhouse gases and will contribute positively to environmental objectives. The methanation of Sokodé's fermentable substrates would produce clean renewable energy available on site without being dependent on imports.5. Acknowledgments

We are grateful for the Head of the Water and Environmental Sanitation Laboratory and Supervisor of this work, Professor Gnon BABA for funding.

\section{References}

[1] World Bank, "Environmental Analysis of Togo with Emphasis on the Agriculture, Energy and Mining Sectors," Lomé, 2010.

[2] Almansour, nergy and environmental assessments of biogas sectors : Approach by standard sector., University of Bordeaux 1., 2011, p. 147.

[3] Klingel, Drainage sludge management., First ed., 2002, p. 63.

[4] Deressa, «Production of Biogas from Fruit and Vegetable Wastes Mixed with Different Wastes.,» Environment and Ecology Research, vol. 3, n¹3, pp. 65-71, 2015.

[5] Mata-Alvarez, «A critical review on anaerobic co-digestion achievements between 2010 and 2013.,» Renewable and Sustainable Energy Review, n¹36, pp. 412-427, 2014.

[6] Walker, « Residual biogas potential test for digestates." OFW004-005.,»Waste and Resources Action Programme, p. 53, 2010.

[7] Eskicioglu, "“Effect on inoculum/substrate ratio on mesophilic anaerobic digestion of bioethanol plant whole stillage in batch mode.,» Process Biochemistry, n²146, pp. 16821687, 2011.

[8] $\mathrm{Hu}$, «Influence of particle size and $\mathrm{pH}$ on anaerobic degradation of celluloseby ruminal microbes.,» International Biodeterioration \& Biodegradation, vol. 3, n¹55, pp. 233 238., 2005.

[9] Huyard, "Anaerobic co-digestion of wastewater sludges and food waste pulp from aunpacking" process: Enhancement of biogas production and co-metabolism.,»IWA, 2012.

[10] Izumi, «"Effects of particle size on anaerobic digestion of food waste.”,» International Biodeterioration \& Biodegradation, vol. 7, n¹64, pp. 601-608., 2010.

[11] Bruni, «Anaerobic digestion of maize focusing on variety, harvest time andpretreatment.,» Applied Energy, vol. 7, n¹87, pp. 2212-2217., 2010.

[12] Pouech, "Interest of co-digestion for the development of slurry and the treatment of fermentable waste at the scale of a territory.," Pig Research Days., $N^{\circ} 137$, pp. 39-44, 2005. 
[13] Akpaki, Physico-chemical characterization of the sludge from Attidjin (prefecture of the Gulf-Togo)., Lomé, Water and Environment Chemistry, 2016, p. 167.

[14] Tcha-thom, Search for a sustainable sector for anaerobic digestion of fruit and abattoir waste from Togo: Assessment of the agronomic potential of digestates on the soils of the Kara region., Geochemistry, 2019, p. 205.

[15] Fréhaut, Study of the biochemical composition of mango (Mangifera Indica L.) according to its stage of maturity., Biological Engineering, 2001, p. 65.

[16] Chanakya, «Micro-scale anaerobic digestion ofpoint source components of organic fraction of municipal solid waste.,» Waste Management, vol. 4, n²129, p. 1306-1312, 2009 .

[17] Nsavyimana, «Anaerobic co-digestion of septic tank drain sludge and fermentable market waste for recovery: Case of Burundi.,» Life sciences: Environmental sciences \& ecology, 2012. 